\title{
Influência da desnutrição promovida pela dieta básica regional sobre o perfil de ácidos graxos do leite materno, o crescimento e o desenvolvimento de ratos jovens ${ }^{1}$
}

\author{
Malnutrition promoted by a basic regional \\ diet alters the fatty acid profile of breast milk, \\ and the growth and development of rat pups
}

Amanda Santos de SOUZA 2

Luciana da Camara PACHECO ${ }^{3}$

Priscila da Silva CASTRO ${ }^{3}$

Maria das Graças TAVARES DO CARMO²

RE S U M O

\section{Objetivo}

Avaliar os efeitos do consumo da Dieta Básica Regional e da reabilitação nutricional, durante os períodos críticos de crescimento e desenvolvimento de ratos, sobre a evolução da sua massa corporal e tecidual, bem como o consumo alimentar de mães durante a gestação e lactação e de seus filhotes, machos e fêmeas, até 70 dias de vida. Adicionalmente, verificou-se o percentual dos ácidos graxos nas dietas experimentais e no leite materno.

\section{Métodos}

Foram utilizados ratos Wistar, de ambos os sexos. Após a constatação da prenhez, as ratas foram divididas em três grupos. 1) Grupo controle, animais alimentados com ração comercial durante o período de gestação e lactação (mães e filhotes) e, após o desmame, os filhotes até 70 dias de vida; 2) Grupo desnutrido, animais alimentados com ração Dieta Básica Regional durante o mesmo período descrito para o grupo controle e 3) Grupo recuperado, animais alimentados com ração Dieta Básica Regional durante o período de gestação e

1 Artigo elaborado a partir de dissertação de A.S. SOUZA, intitulada "Consequêencias da desnutrição na distribuição relativa de ácidos graxos de cadeia longa do sistema nervoso central e no comportamento cognitivo de ratos". Universidade Federal do Rio de Janeiro; 2006.

2 Universidade Federal do Rio de Janeiro, Centro de Ciências da Saúde, Instituto de Nutrição Josué de Castro, Laboratório de Bioquímica Nutricional. Bloco J, Sala J2-021, Cidade Universitária, 21941-902, Rio de Janeiro, RJ, Brasil. Correspondência para/Correspondence to: M.G. TAVARES DO CARMO.E-mail: <tcarmo@editema.com.br>.

3 Universidade Federal do Rio de Janeiro, Centro de Ciências da Saúde, Instituto de Biofísica Carlos Chagas Filho, Laboratório de Neurobiologia da Retina. Rio de Janeiro, RJ, Brasil. 
468 | A.S. SOUZA et al.

lactação e os filhotes, após o desmame, alimentados com ração comercial até 70 dias de vida. Os animais foram monitorados diariamente, aferindo-se a massa corporal e o consumo alimentar. Os filhotes com 70 dias de vida foram sacrificados por decapitação e o cérebro, o coração, o fígado e os rins foram retirados e pesados. Os animais receberam água e ração ad libitum e foram mantidos em biotério com temperatura e luminosidade controladas. Os testes estatísticos utilizados foram o teste $t$ de Student, a Análise de Variância e o pós-teste de Bonferroni.

\section{Resultados}

Foram encontradas alterações importantes no percentual de ácidos graxos essenciais na Dieta Básica Regional, assim como no leite materno das mães desnutridas. O ganho de peso das mães desnutridas e de seus respectivos filhotes, tanto machos quanto fêmeas, foi menor que o de animais controle desde a lactação até o final do experimento. As fêmeas recuperadas apresentaram valores de massa corporal estatisticamente semelhantes aos do grupo controle, o que não foi observado nos filhotes machos do grupo recuperado.

\section{Conclusão}

O comprometimento da massa corporal materna durante a lactação e o déficit na taxa de crescimento dos filhotes, machos e fêmeas, se deveram à ingestão da Dieta Básica Regional multideficiente. A diminuição dos teores de ácidos graxos específicos do leite materno poderia, ainda que não completamente, justificar o déficit de crescimento observado.

Termos de indexação: Ácidos graxos. Alimentação básica. Crescimento. Desnutrição. Estudos experimentais. Leite materno.

\section{A B S T R A C T}

\section{Objective}

The aim of this study was to assess the effects of a basic regional diet and nutritional rehabilitation during the critical growth and development periods of rat pups and their effects on body weight and tissue mass gain; to assess food intakes of dams during gestation and lactation and of male and female pups until they were 70 days old; and to assess the percentages of fatty acids in experimental diets and breast milk.

\section{Methods}

Male and female Wistar rats were used. After mating, pregnant rats were divided into three groups: 1) Control group, consisting of dams from the beginning of pregnancy (21 days) and pups from birth until they were 70 days old (totaling 91 days) fed commercial lab chow; 2) Malnourished group, consisting of dams and pups fed the regional basic diet chow for the same 91 days; and 3) rehabilitated group, consisting of dams fed the regional basic diet during pregnancy and lactation and pups fed commercial lab chow after weaning (at 21 days) until they were 70 days old. The animals received food and water ad libitum and were maintained in a room with controlled temperature and lighting conditions. The animals were monitored daily to record body weight and food intake. At 70 days, the offspring were killed by decapitation and the brain, heart, kidneys and liver were removed and weighed. The results were analyzed using the Student's t-test, analysis of variance and Bonferroni post hoc test.

\section{Results}

Important changes were observed in the percentages of essential fatty acids in the regional basic diet as well as in the milk of malnourished dams. Weight gains of malnourished dams and male and female offspring were lower than those of the controls' from the lactation period until the end of experiment. No differences in body weight were found between the females of the rehabilitated and control groups, but the weight of the male offspring of both groups differed.

\section{Conclusion}

The impaired body weight gain of the dams during lactation and the deficient growth rate of the male and female pups were due to the basic regional diet which lacked many nutrients. The decreased amounts of specific fatty acids in breast milk could partially justify the observed growth deficit.

Indexing terms: Fatty acid. Staple food. Growth. Malnutrition. Experimental studies. Breast milk. 


\section{N T R O D U Ç Ã O}

A desnutrição materna é um fator que contribui significativamente para os elevados índices de mortalidade perinatal e infantil. De acordo com a Organização Mundial da Saúde e a Organização Pan-Americana de Saúde, aproximadamente 174 milhões de crianças abaixo de cinco anos são desnutridas e em muitos países, como na África e no Sul da Ásia, existe alta prevalência de desnutrição em mulheres em idade reprodutiva. No Brasil, estima-se que o número de desnutridos seja maior em áreas rurais, principalmente na Região Nordeste ${ }^{1}$. As conseqüências clínicas da desnutrição dependem de vários fatores, incluindo o grau de severidade e a duração das deficiências nutricionais ${ }^{2}$.

A ingestão materna de dietas nutricionalmente deficientes durante a gravidez e/ou lactação ocasiona efeitos deletérios na prole 3 , principalmente durante o desenvolvimento do Sistema Nervoso Central ${ }^{2}$. Estudos mostraram que alimentar ratas durante a gravidez e a lactação com dietas deficientes em proteína diminui o tamanho da ninhada e a massa corporal de filhotes ${ }^{4,5}$. Hipoplasia e atrofia de tecidos podem ocorrer na deficiência protéico-energética e, dessa forma há diminuição do tamanho corporal e de órgãos ${ }^{6,7}$. Muitos dos efeitos da má nutrição pré-natal e pós-natal são permanentes, ainda que algum grau de melhoramento possa ser produzido por exposição a diferentes estímulos, inclusive ambiental e nutricional2.

A Dieta Básica Regional (DBR) constitui a base da alimentação diária da população desfavorecida da Zona da Mata de Pernambuco. A DBR corresponde a uma dieta multideficiente, pois contém cerca de $8 \%$ de proteínas dos quais a maior proporção é de origem vegetal e $1 \%$ de lipídios. Os ingredientes da dieta $(\mathrm{g} / \mathrm{g} \%)$ são farinha de mandioca $(64,81)$, feijão mulatinho $(18,34)$, batata-doce $(12,76)$ e carne seca $(3,74)$ que foram cozidos, desidratados à $60^{\circ} \mathrm{C}$ e moídos. A DBR tem sido considerada um modelo adequado para estudar os efeitos da desnutrição materna e na prole ${ }^{8}$.
O crescimento e o desenvolvimento dos neonatos estão diretamente relacionados à qualidade e à quantidade do leite materno por eles consumido9. Entre os macronutrientes presentes no leite materno de várias espécies, os lipídios exercem funções de grande relevância, fornecendo $50,0 \%$ a $60,0 \%$ do total de energia contida nesta fonte alimentar essencial para o neonato. Triglicerídeos constituem 98\% dos lipídios presentes, enquanto fosfolipídios 1,0\% e colesterol e seus ésteres $0,5 \%$ \%, 10 .

Os Ácidos Graxos (AG) que compõem os triglicerídeos do leite materno podem ter distintas origens, tais como: dietética, síntese hepática, circulação (ácidos graxos livres liberados do tecido adiposo após lipólise) ou nova síntese pela glândula mamária. Aproximadamente $30 \%$ dos AG do leite derivam diretamente da ingestão dietética ${ }^{11,12}$. Os AG sintetizados na glândula mamária são principalmente de cadeia média (C10:0, C12:0 e $(14: 0)^{11}$ e compreendem cerca de $10,0 \%$ a $12,0 \%$ do conteúdo total de $A G$ do leite ${ }^{11,12}$. Esse tipo de $A G$ representa uma fonte energética de fácil absorção para o lactente ${ }^{13}$. Dietas hipolipídicas e ricas em carboidratos aumentam a síntese destes AG na glândula mamária ${ }^{11}$. Alguns dos ácidos graxos poliinsaturados de cadeia longa (AGPI-CL), tais como o araquidônico (AA, C20:4 n-6) e o derivado do ácido graxo essencial $\alpha$-linolênico, o ácido graxo docosahexaenóico (DHA, C22:6 $n-3)$, também são encontrados no leite, ainda que em menor porcentagem ${ }^{14}$. Na maioria da população Ocidental a concentração média de ácido graxo docosahexaenóico no leite humano está entre 0,2 e 0,4\% e este conteúdo é influenciado pela dieta materna ${ }^{11}$. Esses ácidos graxos são necessários para o desenvolvimento cerebral do neonato, pois participam da mielinização, da proliferação celular e da função retiniana ${ }^{11,14}$.

Não foram encontrados na literatura estudos demonstrando o perfil dos ácidos graxos no leite de animais tratados com a Dieta Básica Regional durante a gestação e a lactação, assim, o objetivo do presente estudo foi avaliar os efeitos 
$470 \mid$ A.S. SOUZA et al.

da desnutrição promovida pelo consumo de Dieta Básica Regional e da reabilitação nutricional, durante a gestação, a lactação e até 70 dias de vida pós-natal sobre a evolução da massa corporal, da massa dos tecidos cerebrais, cardíacos, hepáticos e renais, bem como sobre o consumo alimentar, de ratas gestantes e lactantes e de seus filhotes até 70 dias de vida. Adicionalmente, verificou-se o percentual dos ácidos graxos nas dietas experimentais e no leite materno.

\section{MÉTODOS}

Foram utilizados 133 ratos albinos de linhagem Wistar de ambos os sexos, provenientes do biotério de roedores do Instituto de Nutrição da Universidade Federal do Rio de Janeiro (UFRJ). A manipulação e o sacrifício dos animais seguiram as normas estabelecidas pela Sociedade Brasileira de Neurociências e Comportamento (SBNeC) e foram aprovadas pela comissão de uso de animais experimentais do Instituto de Biofísica Carlos Chagas Filho. Ratas jovens, nulíparas foram submetidas ao acasalamento com ratos de mesma linhagem e origem. A provável prenhez das ratas foi detectada a partir da visualização de espermatozóides na secreção vaginal e a partir deste momento as ratas receberam suas respectivas rações. Ao nascimento, a ninhada foi reduzida a oito filhotes. A mãe do grupo desnutrido que apresentasse comportamento de canibalismo, ou seja, ingerir os filhotes, era descartada e se iniciava um novo acasalamento. Os animais receberam água e ração ad libitum e foram mantidos em biotério com temperatura de $24^{\circ} \mathrm{C}$ (com variação de $2^{\circ} \mathrm{C}$ ) e ciclo claro-escuro de $12 \mathrm{em} 12$ horas.

As ratas grávidas foram subdivididas em três grupos experimentais, a saber: 1) Grupo Controle (GC), animais alimentados com ração comercial (Tabela 1) durante o período de gestação e lactação (mães e filhotes) e, após o desmame, os filhotes até 70 dias de vida; 2) Grupo Desnutrido (GD), animais alimentados com ração Dieta Básica Regional durante o mesmo período descrito para o GC e 3) Grupo Recuperado (GR), animais alimen- tados com ração DBR durante o período de gestação e lactação, e os filhotes após o desmame, alimentados com ração comercial até 70 dias de vida. Durante o período de ensaio, os animais foram monitorados diariamente, aferindo-se a massa corporal e estimando-se o consumo alimentar pela pesagem da ração antes e após a oferta ao animal, calculando-se então a diferença entre esses valores. Os filhotes com 70 dias de vida foram sacrificados por decapitação e o cérebro, o coração, o fígado, o rim direito e o esquerdo foram retirados e pesados em balança digital Coleman modelo PW-1100.

A Dieta Básica Regional (DBR), identificada por inquérito de freqüência de consumo alimentar, realizado pelo Setor de Nutrição Humana da Universidade Federal de Pernambuco, foi confeccionada no laboratório do Instituto de Nutrição da UFRJ, utilizando-se como ingredientes batata-doce (Iponea batatas), feijão mulatinho (Phaseolus vulgaris), farinha de mandioca (Manihot esculenta), carne seca (carne bovina salgada e prensada) e gordura da própria carne ${ }^{8}$. Os ingredientes (exceto a farinha de mandioca) foram cozidos e em seguida secos (desidratados) em estufa com circulação de $\operatorname{ar}\left(50-60^{\circ} \mathrm{C}\right)$, durante, aproximadamente, 24 horas. Em seguida, foram moídos e homogeneizados, acrescentando-se também a gordura do charque, que foi retirada antes do cozimento da carne. Desse modo, a carne foi cozida, seca e moída com o menor conteúdo possível de tecido adiposo. A gordura foi derretida e acrescentada na proporção preconizada pela fórmula. Após os componentes em pó serem homogeneizados fez-se uma pasta, acrescentando-se aos poucos, 845 Desvio-padrão - $\mathrm{DP}=50 \mathrm{~mL}$ de água morna (de $40^{\circ} \mathrm{C}$ a $50^{\circ} \mathrm{C}$ ) para o preparo de $1 \mathrm{~kg}$ de ração. $\mathrm{A}$ massa foi então processada em uma masseira para obtenção de pequenos pedaços (pellets). Os pellets assim obtidos permaneceram em estufa com circulação de $\operatorname{ar}\left(50^{\circ} \mathrm{C}-60^{\circ} \mathrm{C}\right)$ durante, aproximadamente, 24 horas até a sua secagem e solidificação.

A DBR e a ração comercial apresentam em percentagem, respectivamente, os seguintes 
nutrientes: proteínas $(7,87$ e 23,0), carboidratos $(69,67$ e 50,44), lipídios (0,8 e 5,0), fibras (7,21 e $10,0)$ e minerais $(1,26$ e 10,0), para um total de 317,36 e $338,76 \mathrm{kcal}$. Nenhum suplemento vitamínico foi adicionado à dieta ${ }^{8}$.

Aos 14 dias de lactação, ratas lactantes do grupo controle $(n=3)$ e desnutrido $(n=4)$ foram anestesiadas intraperitonealmente com pentobarbital sódico $(30 \mathrm{mg} / \mathrm{kg})$, e receberam ocitocina através das narinas $(1 \mathrm{~mL} / \mathrm{kg})$. O leite foi extraído por compressão manual das tetas, acondicionado em tubos plásticos e estocado a $-70^{\circ} \mathrm{C}$ até a análise de seu conteúdo lipídico. Um total de 300 e $80 \mu \mathrm{L}$ de leite foi extraído de cada rata controle e desnutrida, respectivamente. Após a extração do leite materno as ratas foram sacrificadas por decapitação.

Os lipídios totais foram extraídos segundo Bligh \& Dyer ${ }^{15}$. O leite $(10 \mu \mathrm{L}$ para cada grupo experimental) e as dietas experimentais (200mg) foram pesados e homogeneizados com solução salina $0,9 \%$. Ao homogenato foram adicionados $2 \mathrm{~mL}$ de metanol e $1 \mathrm{~mL}$ de clorofórmio. Após agitação em intervalos de 5 em 5 minutos por um período de 2 horas, o homogenato foi centrifugado, durante 10 minutos, a 3000rpm e o sobrenadante armazenado em geladeira. Ao precipitado resultante no tubo foram adicionados novamente $2 \mathrm{~mL}$ de metanol, $1 \mathrm{~mL}$ de clorofórmio e $0,8 \mathrm{~mL}$ de água, agitados de 5 em 5 minutos por 1 hora e centrifugados durante 10 minutos a 3000rpm. O sobrenadante foi extraído e misturado ao que permaneceu armazenado na geladeira, adicionado de $1 \mathrm{~mL}$ de água e $1 \mathrm{~mL}$ de clorofórmio. Após agitação por 30 segundos e centrifugação por 30 minutos a 3000 rpm, a solução foi separada em duas fases: fase aquosa e fase orgânica que contém os lipídios totais. A fase orgânica foi extraída e seca sob corrente de nitrogênio. A amostra foi então pesada.

A metilação foi feita partindo-se de uma alíquota das amostras de lipídios, do leite ou das dietas experimentais, de acordo com a técnica descrita por Lepage \& Roy ${ }^{16}$, que preconiza o seu tratamento com uma solução de $2 \mathrm{~mL}$ de metanolbenzeno $(4: 1 \mathrm{v} / \mathrm{v})$ e $200 \mu \mathrm{L}$ de cloreto de acetila, acrescentado sob leve agitação. A mistura final contendo os metil-ésteres de ácidos graxos foi estocada em freezer para análise posterior em cromatógrafo a gás.

Os ácidos graxos metilados foram quantificados por cromatografia gasosa em um cromatógrafo Perkin Elmer Autosystem XL, equipado com detector de chama ionizável, ligado a um software Perkin Elmer Nelson - EUA. Os ácidos graxos foram separados em coluna capilar SP-2330 (Supelco Inc., Bellefonte, PA) com $60 \mathrm{~m} \times 0,32 \mathrm{~m}$ de diâmetro interno. Os ésteres foram identificados por comparação com seu tempo de retenção com padrões conhecidos: E6013 cis 5,8,11-Eicosatrienoic acid methyl ester (MEAD), A9298 Arachidonic acid methyl ester 99\%, L2626 Linolenic acid methyl ester, L1876 Linoleic acid methly ester, D2659 cis $4,7,10,13,16,19$ -Docosahexaenoic acid methyl ester, Supelco 37 Component FAME Mix (Sigma, Supelco e Nuchek).

Os resultados foram expressos como média e erro-padrão da média. A análise estatística utilizada foi o teste $t$ de Student para comparar as variáveis entre o grupo controle e o desnutrido e a análise de variância ANOVA de uma via, para comparar os efeitos da recuperação nutricional entre os grupos. Para a comparação entre as médias dos resultados foi aplicado o pós-teste de Bonferroni, adotando-se como nível mínimo de significância o valor de $p<0,05$.

\section{RESULTADOS}

Os resultados apresentados na Tabela 1 correspondem ao percentual de ácidos graxos nas dietas consumidas pelos diferentes grupos experimentais durante o período de estudo. Na dieta Dieta Básica Regional observa-se que o somatório da concentração relativa de ácidos graxos saturados e monoinsaturados foi significantemente maior em relação à dieta controle. No entanto, em relação aos ácidos graxos poliinsaturados, a DBR apresentou valores percentuais significantemente menores. Observa-se também que o percentual do ácido graxo poliinsaturado essencial 
472 | A.S. SOUZA et al.

da família $n-3$, alfa-linolênico, foi significativamente maior na $D B R$, enquanto que os teores de ácido poliinsaturado essencial da família $n-6$, linoléico, foi significantemente menor na dieta DBR. Isto pode ser explicado pelo fato de que a Dieta Básica Regional contém 18,34g de pó de feijão mulatinho, que possui uma grande concentração do ácido graxo alfa-linolênico, já a dieta comercial é preparada com óleo de soja, que é rico em ácido linoléico. Os ácidos graxos poliinsaturados de cadeia longa, como o araqui- dônico e o ácido graxo docosahexaenóico, apresentaram valores percentuais abaixo de 0,50\% e os valores encontrados não foram estatisticamente diferentes entre as dietas.

A Figura $1 \mathrm{~A}$ apresenta os valores médios de consumo alimentar relativo (gramas de ração/ 100 gramas de massa corporal). Observa-se que as mães desnutridas apresentaram consumo alimentar significantemente menor no primeiro e no último dia de gestação em relação ao grupo controle. Como conseqüência das poucas va-

Tabela 1. Percentual de ácidos graxos de dietas experimentais e do leite de ratas Wistar com 14 dias de lactação. Rio de Janeiro (RJ), 2006

\begin{tabular}{|c|c|c|c|c|c|c|c|c|}
\hline \multirow{2}{*}{ Ácidos graxos } & \multicolumn{2}{|c|}{ Dieta comercial $(5)^{1}$} & \multicolumn{2}{|c|}{ Dieta básica regional $(6)^{1}$} & \multicolumn{2}{|c|}{ Leite controle $(3)^{1}$} & \multicolumn{2}{|c|}{ Leite desnutrido $(4)^{1}$} \\
\hline & M & ER & $\mathrm{M}$ & $E R$ & $M$ & ER & $M$ & $\mathrm{ER}$ \\
\hline C 10:0 & \multicolumn{2}{|c|}{ nd } & 0,22 & 0,02 & \multicolumn{2}{|c|}{ nd } & 3,44 & 0,32 \\
\hline C 11:0 & \multicolumn{2}{|c|}{ nd } & \multicolumn{2}{|c|}{ nd } & 0,16 & 0,02 & \multicolumn{2}{|c|}{ nd } \\
\hline C 12:0 & 0,13 & 0,01 & 0,49 & $0,04^{\star \star \star}$ & 2,82 & 0,18 & 6,28 & $0,39^{\star \star \star}$ \\
\hline C13:0 & 0,12 & 0,01 & 0,61 & $0,06^{\star}$ & 0,13 & 0,01 & \multicolumn{2}{|c|}{ nd } \\
\hline C 14:0 & 3,13 & 0,30 & 5,38 & $0,54^{*}$ & 9,61 & 0,91 & 17,68 & $1,15^{\star \star \star}$ \\
\hline C 15:0 & 0,69 & 0,06 & 1,50 & 0,10 & 0,14 & 0,01 & 0,22 & $0,01^{\star \star}$ \\
\hline C 16:0 & 19,63 & 0,31 & 23,07 & $0,66^{\star \star \star}$ & 17,12 & 0,26 & 28,22 & $2,05^{\star \star}$ \\
\hline C 17:0 & 0,14 & 0,01 & 0,45 & $0,04^{\star}$ & 0,89 & 0,09 & 0,28 & $0,02^{\star \star \star}$ \\
\hline C18:0 & 3,54 & 0,13 & 8,02 & $0,41^{\star \star \star}$ & 5,22 & 0,50 & 9,11 & $0,99^{*}$ \\
\hline$C 22: 0$ & \multicolumn{2}{|c|}{ nd } & \multicolumn{2}{|c|}{ nd } & 0,28 & 0,03 & \multicolumn{2}{|c|}{ nd } \\
\hline$C 23: 0$ & \multicolumn{2}{|c|}{ nd } & 0,20 & 00,2 & \multicolumn{2}{|c|}{ nd } & \multicolumn{2}{|c|}{ nd } \\
\hline $\boldsymbol{\Sigma}$ saturados & 27,41 & 0,85 & 39,37 & $0,78^{\star * *}$ & 39,37 & 2,96 & 65,23 & $1,91^{\star \star *}$ \\
\hline C 14:1 & 0,61 & 0,06 & 0,59 & 0,05 & 3,15 & 0,10 & 4,89 & $0,49^{*}$ \\
\hline C 16:1 & 0,68 & 0,06 & 1,44 & $0,10^{\star}$ & 0,20 & 0,01 & 1,61 & $0,08^{\star \star *}$ \\
\hline C $17: 1$ & \multicolumn{2}{|c|}{ nd } & 0,24 & 0,02 & 0,18 & 0,02 & 0,28 & $0,02^{*}$ \\
\hline C18:1 n-9 trans & 0,36 & 0,03 & 0,43 & 0,04 & \multicolumn{2}{|c|}{ nd } & \multicolumn{2}{|c|}{ nd } \\
\hline C18:1 n-9 cis & 20,87 & 1,01 & 23,85 & $0,80^{*}$ & 20,31 & 2,00 & 19,72 & 1,90 \\
\hline C20:1 n-9 & \multicolumn{2}{|c|}{ nd } & \multicolumn{2}{|c|}{ nd } & 0,10 & 0,01 & \multicolumn{2}{|c|}{ nd } \\
\hline C24:1 n-9 & \multicolumn{2}{|c|}{ nd } & 0,08 & 0,00 & 0,11 & 0,01 & \multicolumn{2}{|c|}{ nd } \\
\hline$\Sigma$ monoinsaturados & 22,52 & 1,28 & 25,96 & $0,78^{*}$ & 24,01 & 2,07 & 26,43 & 2,73 \\
\hline C18:2 n-6 cis & 45,48 & 1,15 & 19,66 & $0,85^{\text {** }}$ & 29,92 & 1,00 & 5,47 & $0,53^{\star \star \star}$ \\
\hline C $18: 3$ n-6 & 0,13 & 0,01 & 0,23 & $0,02^{\star \star \star}$ & 0,20 & 0,00 & & \\
\hline$c 20: 2 \mathrm{n}-6$ & 2,87 & 0,20 & \multicolumn{2}{|c|}{ nd } & 0,73 & 0,05 & \multicolumn{2}{|c|}{ nd } \\
\hline$C 20: 4$ n-6 AA & 0,31 & 0,03 & 0,44 & 0,04 & 1,81 & 0,04 & 0,63 & $0,06^{\star \star \star}$ \\
\hline$C 22: 4 n-6$ & & & 0,09 & 0,00 & 0,59 & 0,06 & & \\
\hline$\Sigma \mathrm{n}-6$ & 46,39 & 1,36 & 20,38 & $0,90^{* * *}$ & 33,00 & 0,85 & 6,14 & $0,63^{\star \star *}$ \\
\hline C18:3n-3 & 2,87 & 0,09 & 11,44 & $0,57^{\star \star \star}$ & 1,98 & 0,20 & 0,07 & $0,00^{\star * *}$ \\
\hline C20:5 n-3 EPA & 0,16 & 0,01 & 0,48 & $0,05^{\star \star \star}$ & 0,18 & 0,01 & & \\
\hline$c 22: 5 n-3$ & 0,21 & 0,02 & 0,16 & $0,01^{\star}$ & 0,28 & 0,01 & & \\
\hline C22:6 n-3 DHA & 0,31 & 0,03 & 0,20 & 0,02 & 0,40 & 0,05 & 2,12 & $0,30^{\star \star \star}$ \\
\hline$\Sigma \mathrm{n}-3$ & 3,44 & 0,07 & 12,25 & $0,57^{\star \star *}$ & 2,84 & 0,30 & 2,19 & 0,29 \\
\hline C18:2 n-6/C18:3 n-3 & 15,91 & 0,39 & 1,75 & $0,13^{* * *}$ & 15,80 & 1,60 & 78,14 & $6,90^{\star \star *}$ \\
\hline$n-6 / n-3$ & 13,49 & 0,19 & 1,69 & $0,11^{* * *}$ & 11,62 & 1,18 & 1,92 & $0,19^{* * *}$ \\
\hline$\Sigma$ poliinsaturados & 49,82 & 1,43 & 32,63 & $1,09^{\star \star \star *}$ & 35,84 & 1,09 & 8,33 & $0,86^{* * *}$ \\
\hline
\end{tabular}

1 quantidade de amostras utilizadas. nd: não detectado; AA: ácido araquidônico; EPA: ácido eicosapentaenóico; DHA: ácido docosahexaenóico. Valores representam a média (M) e o erro-padrão (ER) da média. A terceira coluna deve ser comparada com a segunda coluna e a quinta coluna deve ser comparada com a quarta coluna. ${ }^{*} p<0,05,{ }^{* *} p<0,01$ e ${ }^{* * *} p<0,001$ em relação a dieta comercial ou ao leite grupo controle segundo o teste $t$. 
riações da ingestão alimentar materna entre os grupos, não houve diferença significante na massa corporal materna entre o grupo controle e desnutrido durante a gestação (Figura 1B).
Observa-se diminuição significante no consumo alimentar relativo nos dias 1, 14 e 21 de lactação nas mães do grupo desnutrido, em comparação às mães do grupo controle $(p<0,001)$.
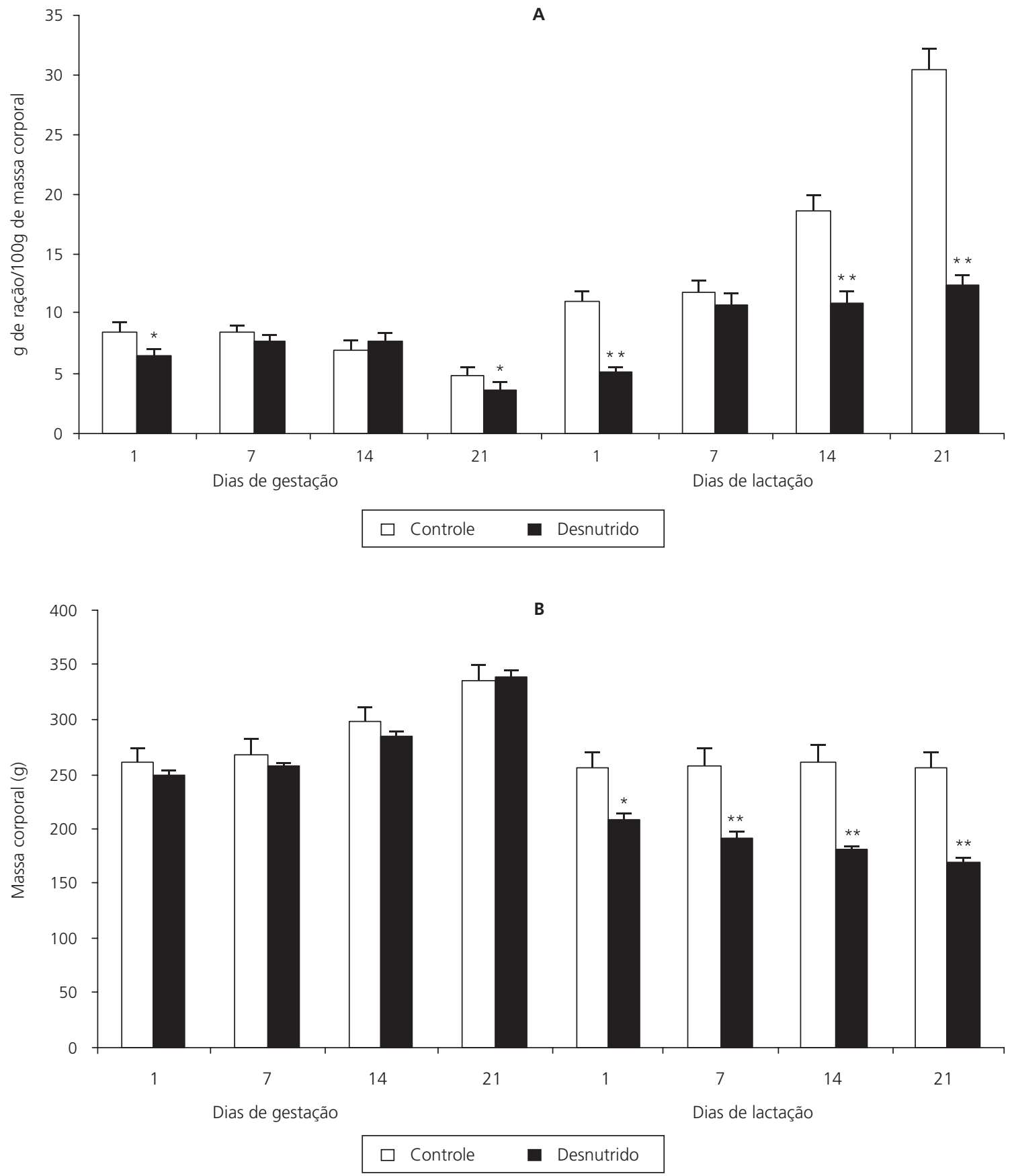

Figura 1. A) Consumo alimentar (g de ração/100g de massa corporal) e B) Evolução ponderal de ratas Wistar durante os períodos de gestação (Controle $n=15$ e Desnutrido $n=17$ ) e lactação (Controle $n=15$ e Desnutrido $n=12$ ). Rio de Janeiro (RJ), 2006.

Nota: Os valores estão expressos como média e erro-padrão da média. Não houve diferença estatística em relação ao grupo controle ( $p>0,05$ ) nas colunas sem asterisco. Houve diferença estatística com ${ }^{*} p<0,05$ e ** $p<0,001$ em relação ao grupo controle segundo o teste $t$ Student. 
Dessa forma, verifica-se que durante todo o período lactacional a massa corporal das mães do grupo desnutrido foi diminuindo gradativamente, apresentando, ao final da lactação, perda de $31,6 \%$ do peso em relação às mães do grupo controle (Figura $1 \mathrm{AB}$ ).

Os valores apresentados na Tabela 1 mostram que o leite das ratas desnutridas apresentou maior percentual de ácidos graxos saturados de cadeia média (C10, 12 e 14) e no somatório de saturados em relação ao leite do grupo controle. Não foi observada, entre os grupos, diferença significante no total de ácido graxo monoinsaturado e no ácido graxo oléico. Com relação aos ácidos graxos poliinsaturados essenciais, observa-se diminuição significante, no leite das ratas desnutridas, dos ácidos graxos linoléico e $\alpha$-linolênico em relação ao grupo controle. Quanto aos ácidos graxos poliinsaturados de cadeia longa, observa-se no leite do grupo desnutrido percentuais signifi- cantemente aumentados de ácido graxo docosahexaenóico (C22:6n-3) e teores diminuídos de ácido graxo araquidônico (C20:4 n-6) em relação ao grupo controle. $\mathrm{O}$ valor percentual total de poliinsaturados foi menor no leite do grupo desnutrido em relação ao grupo controle.

A partir do nascimento já é possível observar diferença significante na massa corporal entre a prole do grupo desnutrido e a do controle, tanto nos machos, quanto nas fêmeas (Figura 2).

A Figura 3A mostra que, ao longo do período estudado, o consumo alimentar relativo dos filhotes machos do grupo desnutrido foi significantemente maior em relação ao controle, exceto aos 35 dias de vida. O grupo recuperado aumentou significantemente o consumo alimentar em relação ao controle nos dias 35, 63 e $70^{\circ}$ de vida pós-natal. Os filhotes machos do grupo desnutrido apresentaram déficit ponderal significativo, quan-

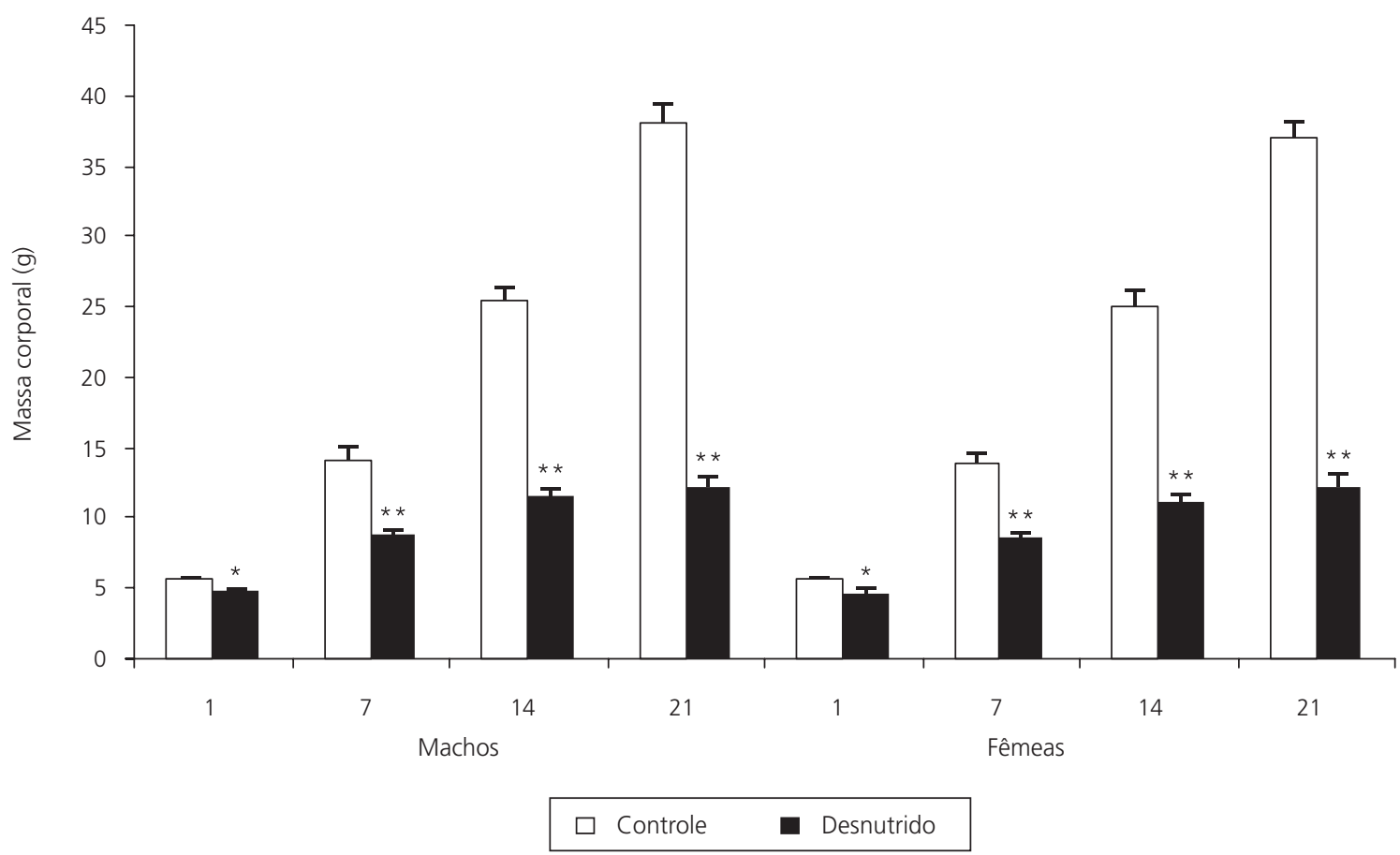

Figura 2. Evolução ponderal de filhotes de ratos Wistar, machos (Controle $n=17$ e Desnutrido $n=15$ ) e fêmeas (Controle $n=14$ e Desnutrido $\mathrm{n}=17$ ), do $1^{\circ}$ aos 21 dias de vida pós-natal, alimentados com Dieta Básica Regional e ração comercial. Rio de Janeiro (RJ), 2006

Nota: Os valores estão expressos como média e erro-padrão da média. * $p<0,01$ e ** $p<0,001$ em relação ao grupo controle segundo o teste $t$ de Student. 
do comparados aos grupos controle e recuperado. Os animais do grupo recuperado apresentaram maior ganho de massa corporal que os animais desnutridos, entretanto a massa corporal final desse grupo foi $28,9 \%$ menor que a do grupo controle (Figura 3B).
A Figura 3A mostra que os filhotes fêmeas do grupo desnutrido consumiram relativamente maior quantidade de ração nos 56,63 e $70^{\circ}$ dia de vida pós-natal em relação ao grupo controle. O grupo recuperado consome menos ração que o grupo controle nos $28,42,49$ e $56^{\circ}$ dia pós-natal.

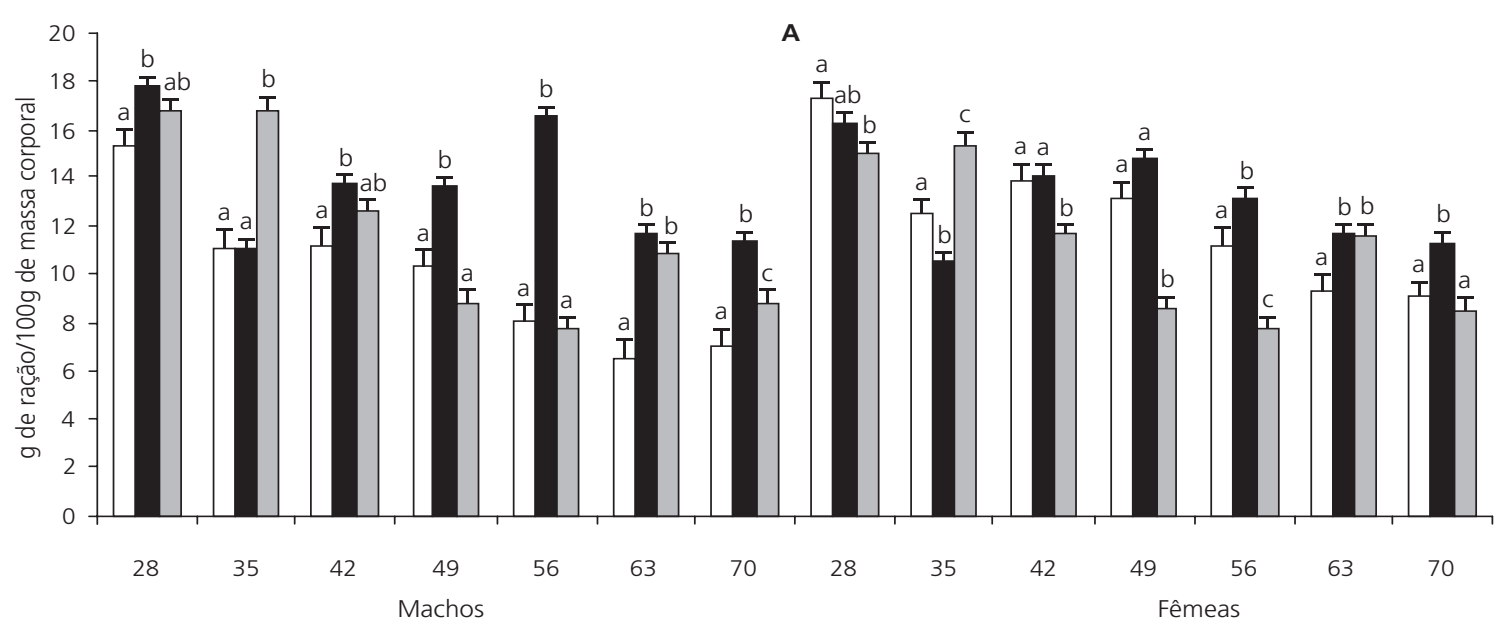

$$
\square \text { Controle } \quad \text { Desnutrido } \square \text { Recuperado }
$$

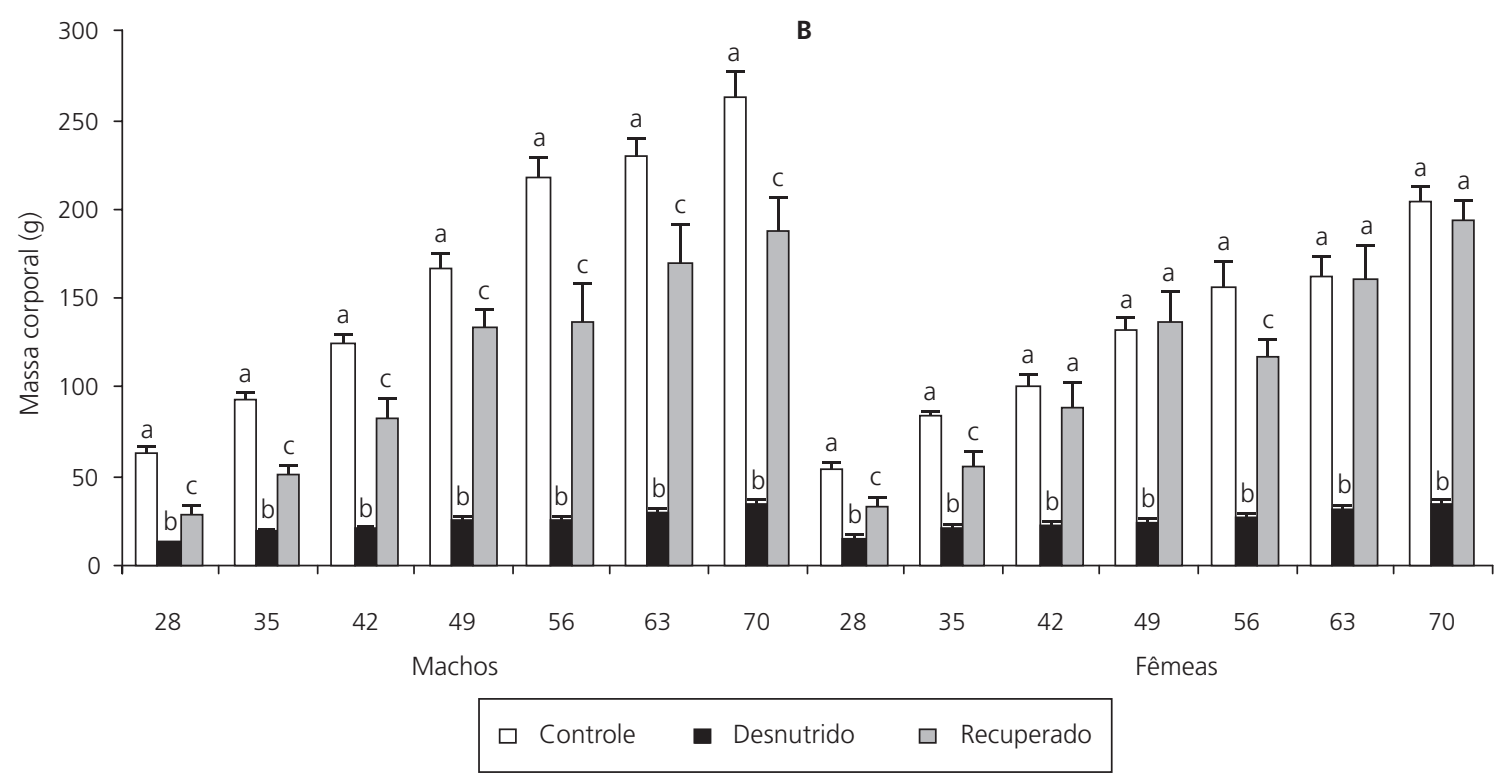

Figura 3. A) Consumo alimentar (g de ração/100g de massa corporal) e B) Evolução ponderal de filhotes de ratos Wistar, machos (Controle $n=17$, Desnutrido $n=15$ e Recuperado $n=14$ ) e fêmeas (Controle $n=14$, Desnutrido $n=17$ e Recuperado $n=17$ ), dos 28 aos 70 dias de vida pós-natal, alimentados com as diferentes dietas experimentais. Rio de Janeiro (RJ), 2006.

Nota: Os valores estão expressos como média e erro-padrão da média. Letras diferentes no mesmo bloco de colunas representam valores estatisticamente diferentes com $p<0,05$ determinado pelo pós-teste de Bonferroni. 
As fêmeas do grupo desnutrido apresentaram menor massa corporal comparadas ao controle e recuperado ao longo do período estudado. A partir dos 42 dias de vida o incremento na massa corporal do grupo recuperado foi semelhante ao do grupo controle, exceto aos 56 dias de vida e esta situação foi mantida até o final do experimento (Figura 3B).

Os resultados apresentados na Tabela 2 demonstram que a massa dos diferentes tecidos nos filhotes machos do grupo desnutrido apresentou-se diminuída em comparação aos grupos controle e recuperado. A massa correspondente ao cérebro, ao coração, ao fígado e aos rins direito e esquerdo dos machos do grupo recuperado foi significantemente maior que a do grupo desnutrido, mas significantemente menor que a do grupo controle, mostrando que a introdução da dieta controle permite o aumento da massa, mas não o suficiente para se igualar ao grupo controle. Quando se avalia a massa relativa dos tecidos, observa-se que somente o cérebro e o coração dos machos do grupo desnutrido apresentam massa significantemente maior que os grupos controle e recuperado. Nos demais órgãos não ocorreram diferenças significantes entre os grupos controle e recuperado.

Com relação às fêmeas, similarmente aos machos, os resultados apresentados na Tabela 2 mostram que a massa dos diferentes tecidos do grupo desnutrido apresentou-se inferior, em comparação aos valores respectivos dos grupos controle e recuperado. A massa dos tecidos das fêmeas recuperadas foi significantemente maior

Tabela 2. Efeito da ingestão das diferentes dietas experimentais sobre a massa do cérebro, do coração, do fígado e dos rins em filhotes de ratos Wistar, machos e fêmeas, com 70 dias de vida. Rio de Janeiro (RJ), 2006.

\begin{tabular}{|c|c|c|c|c|c|c|}
\hline \multirow{2}{*}{ Tecidos (machos) } & \multicolumn{2}{|c|}{ Controle $(17)^{1}$} & \multicolumn{2}{|c|}{ Desnutrido $(15)^{1}$} & \multicolumn{2}{|c|}{ Recuperado $(14)^{1}$} \\
\hline & M & ER & M & ER & M & ER \\
\hline Cérebro (g) & 1,716 & $0,038^{a}$ & 1,193 & $0,037^{\mathbf{b}}$ & 1,566 & $0,032^{c}$ \\
\hline Cérebro (g/100gMC) & 0,650 & $0,010^{a}$ & 3,460 & $0,009^{\mathbf{b}}$ & 0,840 & $0,014^{c}$ \\
\hline Coração (g) & 1,071 & $0,030^{\mathrm{a}}$ & 0,237 & $0,015^{b}$ & 0,708 & $0,029^{c}$ \\
\hline Coração (g/100gMC) & 0,410 & $0,012^{a}$ & 0,690 & $0,008^{b}$ & 0,380 & $0,017^{c}$ \\
\hline Fígado (g) & 11,944 & $0,591^{a}$ & 1,574 & $0,087^{b}$ & 7,138 & $0,419^{c}$ \\
\hline Fígado (g/100gMC) & 4,530 & $0,317^{a}$ & 4,560 & $0,009^{a}$ & 3,810 & $0,213^{a}$ \\
\hline Rim direito (g) & 1,004 & $0,032^{\mathrm{a}}$ & 0,182 & $0,011^{b}$ & 0,750 & $0,043^{c}$ \\
\hline Rim direito (g/100gMC) & 0,380 & $0,017^{a}$ & 0,530 & $0,003^{a}$ & 0,400 & $0,018^{a}$ \\
\hline Rim esquerdo(g) & 1,002 & $0,036^{\mathrm{a}}$ & 0,173 & $0,010^{b}$ & 0,730 & $0,038^{c}$ \\
\hline Rim esquerdo (g/100gMC) & 0,380 & $0,016^{a}$ & 0,500 & $0,002^{a}$ & 0,390 & $0,015^{a}$ \\
\hline \multirow[t]{2}{*}{ Tecidos (fêmeas) } & \multicolumn{2}{|c|}{ Controle (14) } & \multicolumn{2}{|c|}{ Desnutrido (17) } & \multicolumn{2}{|c|}{ Desnutrido (17) } \\
\hline & M & ER & $\mathrm{M}$ & ER & M & ER \\
\hline Cérebro (g) & 1,512 & $0,045^{\mathrm{a}}$ & 1,139 & $0,035^{b}$ & 1,470 & $0,021^{\mathrm{a}}$ \\
\hline Cérebro (g/100gMC) & 0,740 & $0,019^{a}$ & 3,300 & $0,014^{b}$ & 0,760 & $0,011^{a}$ \\
\hline Coração (g) & 0,788 & $0,025^{\mathrm{a}}$ & 0,207 & $0,008^{b}$ & 0,661 & $0,057^{c}$ \\
\hline Coração (g/100gMC) & 0,390 & $0,012^{\mathrm{a}}$ & 0,600 & $0,002^{b}$ & 0,340 & $0,026^{a}$ \\
\hline Fígado (g) & 8,337 & $0,322^{\mathrm{a}}$ & 1,473 & $0,048^{b}$ & 7,064 & $0,505^{c}$ \\
\hline Fígado (g/100gMC) & 4,080 & $0,029^{a}$ & 4,260 & $0,003^{a}$ & 3,660 & $0,075^{a}$ \\
\hline Rim direito $(\mathrm{g})$ & 0,800 & $0,018^{a}$ & 0,169 & $0,005^{b}$ & 0,666 & $0,052^{c}$ \\
\hline Rim direito (g/100gMC) & 0,390 & $0,006^{a}$ & 0,490 & $0,001^{a}$ & 0,350 & $0,017^{\mathrm{a}}$ \\
\hline Rim esquerdo(g) & 0,765 & $0,021^{a}$ & 0,155 & $0,004^{b}$ & 0,630 & $0,051^{c}$ \\
\hline Rim esquerdo (g/100gMC) & 0,370 & $0,008^{a}$ & 0,450 & $0,001^{\mathrm{a}}$ & 0,330 & $0,012^{a}$ \\
\hline
\end{tabular}

${ }^{1}$ quantidade de animais utilizados. g: gramas, g/100gMC: gramas de tecido por 100 gramas de massa corporal.

Os valores estão expressos como média (M) e erro-padrão (ER) da média. Letras diferentes na mesma linha representam valores estatisticamente diferentes com $p<0,05$ determinado pelo pós-teste de Bonferroni. 
que a do grupo desnutrido, porém menor que a do grupo controle. Entretanto, a massa cerebral das fêmeas recuperadas foi igual, estatisticamente, a do grupo controle. A massa dos órgãos das fêmeas do grupo recuperado, quando corrigida pela massa corporal, não diferiu significantemente dos valores do grupo controle.

\section{I S C U S S Ã O}

Com a finalidade de avaliar experimentalmente os efeitos da desnutrição nas mães e em suas respectivas proles sobre aspectos ponderais (corporal e tecidual), bem como sobre o conteúdo de ácidos graxos do leite produzido, administrou-se, durante a gestação, a lactação e após o desmame até 70 dias de vida, a Dieta Básica Regional, uma dieta multideficiente não somente em proteína, como também em lipídios, vitaminas e minerais. A DBR é considerada uma dieta isoenergética, devido ao seu elevado conteúdo de carboidratos, que compensa a redução energética devido a menores teores de lipídios e proteínas, sugerindo assim um modelo de restrição nutricional qualitativo e não energético, similar ao que ocorre na Zona da Mata do Nordeste brasileiro. Além disso, quando foi avaliada a composição dos ácidos graxos da Dieta Básica Regional, constatou-se que além do reduzido conteúdo lipídico, esta dieta apresenta uma composição de ácidos graxos que não satisfaz as necessidades do feto e/ou neonato em desenvolvimento, apresentando menores percentuais de ácidos graxos poliinsaturados e elevadas proporções de ácidos graxos saturados (Tabela 1). Os ácidos graxos poliinsaturados são necessários para a adequada função tecidual e o ótimo crescimento e desenvolvimento do neonato ${ }^{17}$

Em concordância com os resultados de Teodósio et al. ${ }^{8}$, as ratas desnutridas deste estudo apresentaram, ao longo do período gestacional, pouca variação na ingestão alimentar e, portanto, o incremento no ganho de massa corporal (Figura 1) foi semelhante ao do grupo controle. É provável que isto se deva também ao fato de a Dieta Básica
Regional ter sido introduzida no $1^{\circ}$ dia de prenhez, ou seja, quando as reservas maternas de gordura armazenadas no tecido adiposo ainda estavam preservadas, o que difere do estudo de Langley et al. ${ }^{18}$, que introduziram a dieta hipoprotéica antes mesmo do acasalamento e durante a prenhez das ratas. Entretanto, durante o período lactacional detectou-se redução significante na ingestão alimentar e na massa corporal das ratas lactantes tratadas com DBR, em relação ao grupo controle (Figura 1). Como conseqüência, os filhotes das mães alimentadas com a Dieta Básica Regional durante a gestação e a lactação apresentaram taxa de crescimento significantemente menor durante todo o período da lactação em relação aos filhotes de mães controles (Figura 2), sugerindo que a depleção nutricional durante a lactação foi mais prejudicial do que na gestação e interferiu de forma significativa no crescimento da prole.

Em estudo abordando os efeitos de diferentes concentrações de proteína dietética na alimentação de ratas foi observado que, após o parto, as ratas do grupo controle apresentavam $30 \mathrm{~g}$ a mais de peso corporal que na época da concepção, enquanto as mal nutridas apresentaram perda de peso ${ }^{19}$. De fato, prévios estudos sugerem que a ingestão dietética materna é de grande importância no período lactacional, tanto para a saúde da mãe quanto para a performance lactacional e o crescimento das crias. Ratas no pico da lactação (12-14 dias da lactação) mobilizam gordura corporal e proteínas teciduais, acumuladas durante a gestação, para ajudar a manter as necessidades energéticas desse período. A mobilização materna de proteínas teciduais, durante a lactação, é uma alternativa para melhorar o desempenho lactacional principalmente sob condições de inadequada ingestão de nutrientes pela dieta ${ }^{20}$. Neste período, grande parte da energia e dos nutrientes de reserva materna está disponível para manter a produção de leite ${ }^{21,22}$. A restrição alimentar diminui a quantidade de leite produzido e a taxa de crescimento de suas crias $^{23}$.

As dietas nutricionalmente deficientes durante a lactação também podem alterar a 
composição do leite e repercutir no desenvolvimento do lactente. Reconhecendo a importância dos lipídios no período perinatal, dada a sua essencialidade para funções estruturais e regulatórias ${ }^{24}$, foi analisada a composição dos ácidos graxos do leite de ratas lactantes alimentadas com a Dieta Básica Regional. Em geral, as concentrações dos ácidos graxos no leite refletem a composição desses ácidos graxos na dieta materna ${ }^{13}$. Vários trabalhos apontam que dietas ricas em carboidratos favorecem a síntese de ácidos graxos de cadeia média na glândula mamária ${ }^{11}$. De maneira similar, no presente estudo o leite secretado pelas ratas desnutridas, que consumiram uma dieta rica em carboidratos e hipolipídica, apresentou composição em ácidos graxos diferente daquela de mães-controles, por conter teor mais elevado de ácidos graxos de cadeia média (C10:0, C12:0 e C14:0) e menores proporções de ácidos graxos poliinsaturados da família $n-6$ essenciais e de cadeia longa, como o ácido araquidônico (Tabela 1).

Estas diferenças na composição dos ácidos graxos saturados de cadeia média são favoráveis ao neonato, por fornecerem maiores teores de ácidos graxos rapidamente absorvíveis e combustíveis facilmente oxidados ${ }^{13}$ o que, de certa forma, entre outros fatores, poderia garantir a sobrevivência da prole frente a essa situação de grave depleção nutricional. No entanto, os ácidos graxos polienóicos de cadeia longa, principalmente o araquidônico, necessário para o crescimento ${ }^{11,14}$ apresentaram-se severamente depletados no leite do grupo desnutrido. Estes dados permitem sugerir, portanto, que o déficit de crescimento observado nos filhotes do grupo desnutrido ocorreu, pelo menos em parte, por alteração na proporção de araquidônico no leite dessas mães, ocasionando menor disponibilidade desse ácido graxo para o neonato.

Por outro lado, os ácidos graxos poliinsaturados de cadeia longa (AGPI-CL $n$-3), como o ácido docosahexaenóico (C22:6 n-3 DHA), apresentaram-se em maior porcentagem no leite da rata desnutrida em relação ao da rata controle. O ácido docosahexaenóico (C22:6 n-3 DHA) é essencial para o crescimento e o desenvolvimento funcional do cérebro dos neonatos ${ }^{11,14,25}$. No presente estudo, as ratas desnutridas consumiram 20,89g ( $D P=0,88$ ) de Dieta Básica Regional na última semana de amamentação (Figura 1), isto significa dizer que a ingestão diária de DHA foi de 0,042\%. Já o grupo controle consumiu $0,240 \%$ de DHA em $77,22 \mathrm{~g}(\mathrm{DP}=1,69)$ de ração comercial, entretanto a porcentagem de DHA no leite da rata desnutrida foi maior que a do leite da rata controle. É provável que os triglicerídeos armazenados no tecido adiposo materno durante a gestação, contendo DHA, tenham sido mobilizados devido à intensa lipólise, sendo então liberados para a glândula mamária e disponibilizados ao neonato através do leite. Considerando que o ácido docosahexaenóico pode ser formado a partir do ácido graxo essencial $\alpha$-linolênico, pelas vias enzimáticas de dessaturação e alongamento, principalmente hepática, é possível que a maior proporção do ácido graxo $\alpha$-linolênico (C18:3 n-3) verificada na Dieta Básica Regional em relação à ração comercial, $11,44 \%$ e $2,87 \%$, respectivamente (Tabela 1), ao ser dessaturado e alongado no tecido hepático, também poderia contribuir para o suprimento de ácido docosahexaenóico para o leite das ratas desnutridas. Análises complementares como, por exemplo, da atividade das enzimas dessaturases no fígado, são necessárias para melhor elucidar estes achados.

Quando foi avaliada a prole de machos e fêmeas após o desmame até a idade jovem (70 dias), observou-se que os filhotes, machos e fêmeas, de mães desnutridas que receberam a Dieta Básica Regional, apesar de consumirem quantitativamente mais ração que o grupo controle, não recuperaram a massa corporal ao longo do período do estudo (Figura 3), apresentando um déficit na massa corporal significante na idade jovem em relação aos grupos controle e recuperado. De maneira similar, a massa tecidual também foi significantemente afetada, de modo que os machos desnutridos deste estudo apresentaram 
perda de $86,8 \%$ na massa do fígado (Tabela 2) com redução de 86,9\% na massa corporal (Figura 3). Estes achados diferem dos de Boza et al. ${ }^{26}$, que observaram valores $30,0 \%$ menores no peso do fígado e $14,5 \%$ na massa corporal na desnutrição causada pela restrição dietética. Observa-se que na análise da massa de tecidos por 100 gramas de massa corporal, o cérebro e o coração dos machos do grupo desnutrido apresentaram maior peso comparativamente aos grupos controle e recuperado, mostrando que a desnutrição preserva a massa de órgãos com função primordial, como já havia sido descrito por Parra et al..27, de modo que na desnutrição há, prioritariamente, perda de massa hepática para garantir a disponibilidade de energia aos órgãos mais vitais, como o cérebro e o coração.

No grupo recuperado, os machos apresentaram incremento gradativo na massa corporal durante a recuperação nutricional, sem que houvesse grandes variações no consumo alimentar em relação ao grupo controle (Figura 3). Comportamento semelhante foi observado no estudo de Nunes et al..$^{7}$ os quais acompanharam os animais até 30 dias de idade. A persistência de diferenças na massa corporal em relação ao grupo controle, mesmo após reabilitação nutricional, por tempo mais prolongado, também foi observada por outros pesquisadores, em ratos machos na idade de 90 $\operatorname{dias}^{28}$ e 120 dias $^{29}$. Estes resultados não surpreenderam, visto que o déficit de massa corporal induzido pela restrição protéica em fase de crescimento rápido não consegue ser completamente restabelecido por uma dieta normal ${ }^{30}$. Além disso, observaram-se alterações na massa absoluta dos órgãos, no entanto, em termos proporcionais a massa do cérebro ( $\mathrm{g} / 100 \mathrm{~g}$ massa corporal) foi preservada nas fêmeas do grupo recuperado (Tabela 2), confirmando estudos anteriores que sugerem a existência de mecanismos capazes de proteger tecidos essenciais como o cérebro ${ }^{27}$.

No trabalho de Nunes et al. ${ }^{7}$ não foi verificada diferença significante entre machos e fêmeas em relação à massa corporal, após a reabilitação nutricional, de modo que para ambos os sexos essa variável foi significantemente menor em relação ao grupo controle. No entanto, os resultados do presente estudo com a Dieta Básica Regional mostram que, diferentemente do que ocorre com os machos, as fêmeas recuperadas apresentaram menor consumo alimentar e incremento na massa corporal que estatisticamente se assemelham ao do grupo controle a partir do $42^{\circ}$ dia de vida, exceto aos 56 dias (Figura 3). Já com relação à massa dos órgãos aos 70 dias, nota-se que em termos proporcionais as massas de todos os órgãos não diferiram das respectivas do grupo controle (Tabela 2), incluindo o cérebro. Seria interessante realizar estudo posterior com este modelo experimental para avaliar a composição corporal. Com a determinação do conteúdo de gordura e proteína da carcaça seria possível obter uma melhor compreensão acerca da compartimentalização da massa corporal das fêmeas do presente estudo, em termos de percentuais de massa gorda e magra.

Em conclusão, os resultados deste estudo sugerem que a desnutrição durante o período pré e pós-natal, promovida pela Dieta Básica Regional, compromete a massa corporal materna durante a lactação e repercute em notório déficit na taxa de crescimento dos filhotes lactentes, o que, entre outros fatores, poderia ser devido a uma redução no conteúdo ou alteração da proporção entre os diferentes tipos de ácidos graxos do leite materno, principalmente araquidônico, reconhecidos essenciais para o crescimento do neonato. Além disso, a reabilitação nutricional iniciada após o desmame produz efeitos diferentes na massa corporal e de órgãos dos filhotes, machos e fêmeas na idade jovem, sendo estes parâmetros mais comprometidos nos filhotes machos do que nas fêmeas. Estes resultados reforçam o conceito segundo o qual a restrição nutricional qualitativa durante 0 período perinatal altera, em idades mais tardias, o desenvolvimento da prole, e de maneira diferenciada entre os sexos. 
$480 \mid$ A.S. SOUZA et al.

\section{A GRADECIMENTOS}

Ao Programa Institucional de Bolsa de Iniciação Científica, ao Conselho Nacional de Desenvolvimento Científico e Tecnológico, à Universidade Federal do Rio de Janeiro e à Coordenação de Aperfeiçoamento de Pessoal de Nível Superior, pelas bolsas concedidas às alunas de Iniciação Científica e Mestrado, respectivamente.

\section{COLABORADORES}

A.S. Souza contribuiu com o acompanhamento dos animais, a elaboração da Dieta Básica Regional, a análise estatística, a interpretação dos dados e a redação do manuscrito. L.C. Pacheco e P.S. Castro contribuíram com o acompanhamento dos animais. M.G. Tavares do Carmo contribuiu com a orientação da Dissertação de Mestrado, a redação e a revisão do manuscrito.

\section{REFERÊ NCIAS}

1. World Health Organization. The world health report: childhood and maternal undernutrition. [cited 2002 Dec 17]. Available from: <http://www. who.int/aboutwho/en/promoting/nutrition. htm>.

2. Morgane PJ, Austin-Lafrance R, Bronzino J, Tonkiss J, Díaz-Cintra S, Cintra L, et al. Prenatal malnutrition and development of the brain. Neurosci Biobehav Rev. 1993; 17(1):91-128.

3. Zeman FL. Effect on the young rat of maternal protein restriction. J Nutr. 1967; 93(2):167-73.

4. Seegers $\mathbf{W H}$. The effect of protein deficiency on the course of pregnancy. Am J Physiol. 1937; 119(2):474-80.

5. Curtiss C. Effects of a low protein intake on the pregnant rat. Metabolism. 1953; 2(4): 344-58.

6. Madi K, Campos SD. Desnutrição experimental: resultados anátomo-patológicos e bioquímicos da administração de dietas hipoprotéicas a ratos albinos jovens. Mem Inst Oswaldo Cruz. 1975; 73(3):153-81.

7. Nunes ML, Batista BB, Mcheli F, Batistella V. Effects of early malnutrition and nutricional rehabilitation in rats. J Ped. 2002; 78(1):39-44.

8. Teodósio NR, Lago ES, Romani SAM, Guedes RCA. A Regional basic diet from Northeast Brazil as a dietary model of experimental malnutrition. Arch Latinoam Nutr. 1990; 40(4):533-47.
9. Nicholas KR, Hartmann PE. Milk secretion in the rat: progressive changes in milk composition during lactation and weaning and the effect of diet. Comp Biochem Physiol A Mol Integr Physiol. 1991; 98(3-4):535-42.

10. Buison A, Lu H, Guo F, Jen C. High-fat feeding of different fats during pregnancy and lactation in rats: effects on maternal metabolism, pregnancy outcome, milk and tissue fatty acid profiles. Nutr Res. 1997; 17(10):1541-54.

11. Lauritzen L, Hansen HS, Jorgensen MH, Michaelsen KF. The essentiality of long chain $n-3$ fatty acids in relation to development and function of the brain and retina. Prog Lipid Res. 2001; 40(1-2):1-94.

12. Anderson NK, Beerman KA, McGuire MA, Dasgupta N, Griinari JM, Williams J, et al. Dietary fat type influences total milk fat content in lean women. J Nutr. 2005; 135(3):416-21.

13. Neville MC, Picciano MF. Regulation of milk lipid secretion and composition. Ann Rev Nutr. 1997; 17:159-83.

14. Makrides M, Neumann M, Simmer K, Gibson R, Pater J. Are long-chain polyunsaturated fatty acids essential nutrients in infancy? Lancet.1995; 345(8963):1463-8.

15. Bligh EG, Dyer WJ. A rapid method of total lipid extraction and purification. Can J Biochem Physiol. 1959; 37(8):911-7.

16. Lepage G, Roy CC. Direct transesterification of all classes of lipids in a one-step reaction. J Lipid Res. 1986; 27(1):114-20.

17. Sellmayer A, Koletzko B. Long-chain polyunsaturated fatty acids and eicosanoid in infants-physiological and pathophysiological aspects and open questions. Lipids. 1999; 34(2):199-205.

18. Langley SC, Phillips GJ, Jackson AA. In utero exposure to maternal low protein diets induces hypertension in weanling rats, independently of maternal blood pressure changes. Clin Nutr. 1994; 13:319-24.

19. Marín MC, De Tomas ME, Serres C, Mercuri O. Protein-energy malnutrition during gestation and lactation in rats affects growth rates, brain development and essential fatty acid metabolism. J Nutr. 1995; 125(4):1017-24.

20. Pine AP, Jessop NS, Oldham JD. Maternal protein reserves and their influence on lactational performance in rats. Br J Nutr. 1994; 71(1):13-27.

21. Picciano MF. Pregnancy and lactation: physiological adjustments, nutritional requirements and the role of dietary supplements. J Nutr. 2003; 133(3): 1997-2002. 
22. Araya JA, Barriga CP. Efecto de la preñez y la lactancia en el estado nutricional de los acidos grasos esenciales, en la rata. Rev Med Chile. 1996; 124:923-7.

23. Rasmussen KM. Effects of under- and over nutrition on lactation on laboratory rats. J Nutr. 1998; 128(Suppl.2):390S-3S.

24. Innis SM. Polyunsaturated fatty acids in human milk: an essential role in infant development. Adv Exp Med Biol. 2004; 554:27-43.

25. Marszalek JR, Lodish HF. Docosahexaenoic acid, fatty acid-interacting proteins, and neuronal function: breastmilk and fish are good for you. Ann Rev Cell Dev Biol. 2005; 21:633-57.

26. Boza JJ, Moennoz D, Vuichoud J, Jarret AR, Gaudard-de-Weck D, et al. Food deprivation and refeeding influence growth, nutrient retention and functional recovery of rats. J Nutr. 1999; 129(7): 1340-6.

27. Parra MO, Hernandez-Blaquez FJ, Souza e Silva RAP, Silva JRMC, Peduto L. Reduction of liver mass due to malnutrition in rats. Correlation with emaciation of animals and size of organs not inserted in the portal system. São Paulo Med. 1995; 113(3): 903-9.

28. Sharma SK, Behari M, Maheshwari MC, Selvamurthy W. Seizure susceptibility and intrarectal sodium valproate induced recovery in developing undernourished rats. Indian J Med Res. 1990; 92:120-7.

29. Campos DG, Madi K. Studies on pre and post-natal malnutrition in albino rats. Partial ponderal and biochemic recuperation. Rev Bras Pesq Med Biol. 1975; 8(3-4):301-6.

30. Ventrucci G, Ramos LGS, Roston MAM, Gomes MCM. Effects of a leucine-rich diet on body composition during nutritional recovery in rats. Nutrition. 2004; 20(2):213-7.

Recebido em: 3/9/2007

Versão final reapresentada em: 12/8/2008

Aprovado em: 9/2/2009 